Journal of Sea Research

\title{
Sole larval supply to coastal nurseries: Interannual variability and connectivity at interregional and interpopulation scales
}

\author{
Savina-Rolland Marie ${ }^{1,{ }^{*}}$, Lunghi M. ${ }^{1,2}$, Archambault B. ${ }^{2}$, Baulier Loic ${ }^{2,3}$, Huret Martin ${ }^{3}$, \\ Le Pape Olivier ${ }^{2,}$
}

${ }^{1}$ IFREMER, Channel and North Sea Fisheries Department, 150 Quai Gambetta, B.P. 699,F- 62321 Boulogne sur Mer, France

${ }^{2}$ AGROCAMPUS OUEST, UMR985 ESE Ecologie et santé des écosystèmes, F-35042 Rennes, France

${ }^{3}$ IFREMER, STH/LBH, BP 70, F-29280 Plouzané, France

* Corresponding authors : Marie Savina-Rolland ; Olivier Le Pape

\begin{abstract}
:
Simulating fish larval drift helps assess the sensitivity of recruitment variability to early life history. An individual-based model (IBM) coupled to a hydrodynamic model was used to simulate common sole larval supply from spawning areas to coastal and estuarine nursery grounds at the meta-population scale (4 assessed stocks), from the southern North Sea to the Bay of Biscay (Western Europe) on a 26-yr time series, from 1982 to 2007. The IBM allowed each particle released to be transported by currents, to grow depending on temperature, to migrate vertically depending on development stage, to die along pelagic stages or to settle successfully on a nursery, representing the life history from spawning to metamorphosis. The model outputs were analysed to explore interannual patterns in the amounts of settled sole larvae at the population scale; they suggested: (i) a low connectivity between populations at the larval stage, (ii) a moderate influence of interannual variation in the spawning biomass, (iii) dramatic consequences of life history on the abundance of settling larvae and (iv) the effects of climate variability on the interannual variability of the larvae settlement success.
\end{abstract}

\section{Highlights}

- We simulated the drift trajectories of sole eggs and larvae at large spatial (four stocks) and temporal (26 y) scales; We used an IBM coupled online to a hydrodynamic model; $>$ We emphasized: The very low to moderate connectivity between populations at the larval stage $>$ The moderate influence of spawning biomass variations on recruitment $\boldsymbol{~ T h e ~ i n f l u e n c e ~ o f ~ l i f e ~ h i s t o r y ~ a n d ~ c l i m a t e ~ v a r i a b i l i t y ~ o n ~ t h e ~ a m o u n t ~ o f ~}$ settled sole.

Keywords: hydrodynamic model, individual-based model, larval supply, nursery grounds, recruitment variability, Solea solea, metapopulation, English Channel, Bay of Biscay, southern North Sea 


\section{Introduction}

A majority of marine fish species produce a high number of eggs with a low and variable probability of survival, i.e., survival rates close to 1/1000 from spawning to the end of larval stages (Juanes, 2007; Le Pape and Bonhommeau, 2015). The high sensitivity of larval survival to hydrodynamics and environmental conditions causes large variations in recruitment (Daewel et al., 2011) and largely explain the lack of significant stock-recruitment relationships for marine exploited fish (VertPre et al, 2013; Cury et al., 2014; Szuwalski et al 2014). Indeed, most of the recruitment variability of marine fishes is explained by variations in larval survival rates (Levin and Stunz 2005; Houde 2008).

The recruitment variability is lower in populations with large density-dependent effects at juvenile stage (Iles and Beverton 2000), in which case the capacity of nursery habitats has a significant effect (Johnson 2007). This is the case for pleuronectiforms (Archambault et al., 2014). However these species also have an r-oriented strategy at larval stages (an order of magnitude of $10^{-3}$ for survival rate at larval stages for various populations of pleuronectiforms, similar than for other marine fish orders; Le Pape and Bonhommeau, 2015) and their recruitment relies on processes generating high variability during their pelagic life, before metamorphosis and transfer to benthic habitats (van der Veer et al., 2000). The predictive power of the stock-recruitment relationship is very weak for flatfish and this weakness is partly linked to variability at larval stages (Archambault et al., 2014).

With regards to their large influence on recruitment at settlement stages for flatfish, a better understanding of larval processes would help to estimate the number of larvae successfully reaching nursery grounds, to identify the factors generating the associated spatio-temporal variability and 
their consequences for recruitment (Stige et al., 2013), as well as for population structure (Buckley et al., 2008; Wilber et al., 2013).

However, as short term variations associated with mortality and advection are high, reliable in situ data are scarce and the use of larval drift model appears especially appropriate (Gallego et al., 2012). Indeed, larval drift individual based models (IBM) have proved useful to investigate the influence of hydrodynamics on ecology of flatfish larvae. They have been used to study the effects of spawning dynamics (Rochette et al., 2012), hydrodynamics and larval behaviour (Fox et al., 2006; Sentchev and Korotenko, 2007; Bolle et al., 2009), dispersal kernels (Koutsikopoulos et al., 1991; Sentchev and Korotenko, 2005) or connectivity within a population (Rochette et al., 2012) or a meta-population (Savina et al., 2010). However, most of these studies were conducted on relatively short periods of time and/or limited spatial scales. The use of numerical simulations over longer time series, at large scale covering several populations, could provide useful tools to study spatio-temporal variability in dispersal at larval stages and settlement success on suitable nursery habitats, and their consequences on recruitment dynamics and metapopulation structure.

The common sole (Solea solea, L.) is an important commercial flatfish resource with a large range of distribution, from North Western Africa and Mediterranean Sea to the Baltic Sea (Wheeler, 1978). With variations along its latitudinal range, the common sole spawns from winter to spring, pelagic larvae dwell during several weeks ( $\approx 1-2$ months; Rochette et al., 2012) and newly metamorphosed individuals settle in coastal and estuarine areas, which act as exclusive nursery grounds for about 2 years, before sexual maturity (Dorel et al., 1991; Riou et al., 2001). Recruitment variability, although moderate with regard to many marine fish species, is high for the common sole (Le Pape et al., 2003), with a high influence of hydro-climate on larval transport and larval supply (Savina et al., 2010; Rochette et al., 2012). 
To explore the potential effects of hydrodynamics from spawning to metamorphosis of sole larvae over nurseries and the associated large scale spatio-temporal variability, larval supply was simulated using a three dimensional hydrodynamic model. The aim was to simulate sole larval supply in coastal and estuarine nursery areas on a wide scale covering four fished sole stocks-populations (ICES, 2014ab), from the Bay of Biscay to the southern North Sea over a long period of time (19822007). An individual based particle-tracking module was used to simulate larval drift and survival under realistic biological processes from egg to benthic settlement on estuarine and coastal areas. Patterns of spawning, larval settlement success and dispersal, and sensitivity to hydrodynamics variability, were assessed at population scale, and the consequences on recruitment dynamics and metapopulation structure were analysed.

\section{Methods}

The approach combined a hydrodynamic model with a particle-tracking module including previously described eggs and larval behaviour to simulate spawning and hatching of eggs, larval drift, growth and settlement on coastal and estuarine nursery grounds under realistic hydro-climatic conditions. Particles were released according to the spawning season and spatial distribution of eggs. The development (growth), swimming behaviour, benthic settlement and survival of each particle were modelled in parallel with its transport in the hydrodynamic model.

As the present model relies mainly on a previous approach on a restricted spatiotemporal scale in the Eastern English Channel (Rochette et al., 2012), the explanations about model structure and parametrization were summarised. Details are provided only when the model options have been modified, especially with regards to the extent of the study area and the input of new data. For further information please refer to the seminal approach of Rochette et al. (2012). 


\subsection{Hydrodynamic model}

The three dimensional (3D) ocean circulation model MARS (hydrodynamic Model for Application at Regional Scale; Lazure and Dumas, 2008) was used to simulate hydrodynamics from the Bay of Biscay to the southern North Sea (Fig. 1) during 26 years. The model used a $4 \mathrm{~km}$ horizontal resolution with 30 vertical generalized sigma layers. A time step of about 2 minutes allowed the model to solve the strong tidal currents occurring in many parts of the continental shelf of Western Europe, with respect to stability criteria. Atmospheric forcing was extracted from the NCEP-CFSR database (Saha et al., 2010). River discharges were upgraded from those in Huret et al. (2010) and Rochette et al. (2012), and interannual variability at open boundaries for temperature and salinity provided by a global circulation model solution ORCA from the OPA-NEMO model (Michel et al., 2009). The simulation period 1982 - 2007 was the longest allowing for consistent available forcing conditions (river, open boundary and atmospheric).

\subsection{Larvae model}

A particle-tracking module was coupled on-line to the 3D hydrodynamic model as in Huret et al. (2010). This module simulates trajectories and life traits of released particles (Ayata et al., 2010), from spawning areas to nursery grounds (Rochette et al., 2012). A random walk is considered for vertical mixing following Visser (1997), using the vertical eddy diffusivity compiled by the hydrodynamic model and interpolated at the particle depth (see Huret et al., 2010 for additional details).

The spatio-temporal variability of spawning and the larvae natural mortality were implemented in a post-treatment analysis by applying a posteriori weighting factors to released particles (Fox et al., 2006):

(1) Each particle released in a given point at a given date in a given year in the 3D model is a superindividual, representing a certain number of eggs having the same initial conditions. 
(2) The model simulates, for each particle, a trajectory, as well as a survival probability for the egg stages.

(3) The number of surviving larvae is then calculated (post-processed) by taking into account: the number of eggs corresponding to each particle released in the model (post-processed), the survival probability throughout the different eggs stages (simulated), the survival probability throughout larval stages (post-processed), and the final position of the particle (i.e., inside or outside a suitable nursery area, simulated).

\section{Initial conditions: spatial and temporal variability of egg release}

Patches of particles (i.e., super individual) covering the soft bottom grounds of the entire study area was released every $4 \mathrm{~km}$ and every 2 weeks (i.e., on the $10^{\text {th }}$ and $25^{\text {th }}$ of each month at 23:00) during the whole spawning season (in compliance with the preliminary testing carried out in Rochette et al. (2012) on the influence of frequency and number of particles released and the trade-off with the constraints of computing time). Given the eggs buoyancy (Koutsikopoulos et al. 1991), particles were released at 5 meters depth. Around 9000 particles were released for each year simulated.

Each particle represented a number of eggs calculated on the basis of (i) the total number of eggs spawned each year and (ii) the spatio-temporal distribution of eggs within the year. For each stock (i.e., Bay of Biscay BoB, Western English Channel WC, Eastern English Channel EC, southern North Sea NS), the total number of eggs released each year (Fig. S1) was calculated from the number and age structure of adults in each population (ICES, 2014ab), accounting for the female fraction, the number of eggs at age per female and the proportion of mature females (Rochette et al., 2012). Each patch of particles released every 15 days along the spawning period represented a proportion of the total number of eggs spawned in a year by one population and was distributed in space. The spatiotemporal weighting factors were the combination of time and space weighting factors, standardized to a sum of 1 , and then multiplied by the number of eggs spawned that year in this population. 
Time weighting factor: In the EC, the sole spawning period is correlated to sea surface temperature (van der Land, 1991). For each year, a dome shaped curve of spawning temporal dynamics was defined from a previously established model (ICES, 1992) and fitted on the temperature simulated by the 3D numerical model (Rochette et al., 2012). Fincham et al. (2013) estimated the timing of spawning in sole and its interannual variability and trends, including the WC and EC and the NS populations. Based on their analysis, a similar dome shaped spawning curve was set for the WC (i.e., the spawning peak occurring 15 days earlier than in the EC) and the NC (the spawning peak occurring 31 days later, Fig. S2). In the BoB, the pattern of egg production is considered fixed, the deep spawning areas for this population (Arbault et al. 1986) being dramatically less subject to major interannual temperature changes. Data of daily egg production in the BoB (a dome shaped curve of spawning temporal dynamics was defined from January to May 1982; Arbault et al. 1986) were used to fit a model and calculate the daily egg production.

Spatial weighting factor: The spatial weighting factors standing for the spatial distribution of eggs were considered constant over years but varied along the spawning season (Rochette et al., 2012). Monthly egg maps were derived from previous survey data (ICES (1992) for WC and EC, and Arbault et al. (1986) for BoB), by kriging. A classical kriging approach was used on log-transformed egg densities with a common exponential variogram (Matheron, 1963; Clark, 1979) and interpolations until a distance of $20 \mathrm{~km}$. The kriged maps were used to weight the particles released at a given date in each of the four regions/stocks. As patches were released every 15 days in the model, particles of intermediate patches were weighted according to the average egg distribution of the previous and the following survey (Rochette et al., 2012).

The spatial weighting applied for egg patches released in the southern North Sea is slightly different, since the area covered by the model represents only a part of the distribution area of the sole stock in the North Sea. Only the fraction of individuals (eggs) released in the southernmost part of the North 
Sea were considered. Because stock assessments are carried out at the scale of the ICES Subdivision

IV, the proportion of the total egg production released in these patches must be derived. This proportion fluctuates during the spawning season. Egg production models are fitted for each subarea of the North Sea defined in ICES (1992). Then, the ratio of the production in the region located south from $52^{\circ} \mathrm{N}$ (in which egg patches are released, Fig.1) over the total egg production is derived.

Previous analyses were conducted (Rochette et al., 2012) to validate the spatial distribution of eggs. Spawning distribution is supposed to fit the distribution of the adult population during the spawning season (Loots et al., 2009) hence with the related fisheries. Monthly distributions of the 1991 egg survey (ICES, 1992) were compared to annual catches of professional fishermen during the spawning season. This demonstrated a good overlap in seasonal distribution and suggested the interannual steadiness of the monthly spawning distributions (Loots et al., 2009).

\section{Life history during larval drift}

The larval biology model is almost exactly the same as in Rochette et al. (2012); only a summary is given here together with a description of the few changes made to it.

The particle status evolves during the drift through five successive development stages: passive transported eggs, passive transported larvae at development stage 1, vertical migrating larvae from stage 2 onward, larvae at metamorphosis and settled larvae (Table 1).

Eggs -> Larvae 1: Four egg development stages were distinguished. Eggs were assumed to ascend to the surface during the first three development stages through buoyancy (as opposed to having a fixed ascension speed in Rochette et al 2012). The buoyancy model calculates the ascent velocity resulting from the difference between egg density and water density at the egg location in the water column, based on Stoke's formulation as described in Petitgas et al. (2006). The egg location results from the balance between buoyancy forces and vertical mixing applied through the random walk. 
Larvae 1 -> Metamorphosis: Four larval stages were distinguished, as in Rochette et al. (2012). However, vertical diel migration are now triggered by luminosity thresholds (Blaxter 1969; Sundelof et Jonsson, 2012; Kunze et al, 2013), fitted on luminosity used as forcing variable in the 3D numerical model (they started and ended at fixed hours in Rochette et al, 2012). The modelled irradiance is used to derive luminosity. The length waves of the photoscopic (cone-based, as no rods are present, cf Blaxter 1969) light spectrum are used for the conversion from W. $\mathrm{m}^{-2}$ to lux. Luminosity thresholds were found in Blaxter (1969).

The swimming speed (in Body length per second, 1BL/s) is now 1BL/s (ascent) and 0.5BL/s (descent) (Ryland 1963; Savina et al. 2010), rather than 1 BL/s at all time in Rochette et al (2012). The reason behind this choice is that, though the cruising speed is probably higher, the period of sustained swimming is rather short (max 40s observed by Ryland 1963).

Larval mortality: The survival probability was calculated on the duration of the entire larval stage until metamorphosis, specific for each trajectory. Mortality was fixed at 0.09 day $^{-1}$ according to previous estimates for sole (Koutsikopoulos et al., 1991; Horwood, 1993; Lund et al., 2008) and calibration, i.e., so that the average survival rate (i.e., number of settling larvae over the number of eggs spawned) was in the order of magnitude suggested in Le Pape and Bonhommeau $\left(10^{-3}, 2015\right)$. This "calibration objective" is the same as in Rochette et al (2012), the significant loss of larvae due to their drift out of the model domain (towards the NS) explains the lower mortality value found in their case.

Larval settlement and end of simulations: To avoid the spurious simulation of larval behaviour over coastal areas, the model tested whether larvae reach the coastal strip before metamorphosis. Hence, the fine scale destination on the nursery grounds was not targeted and larval supply was estimated at the scale of each nursery area (Fig. 1). In the model, larvae at stage 2 or higher were transported until they reached suitable nursery ground, i.e., soft-bottomed coastal area within the 20-m isobath 
(Riou et al, 2001; Lacroix et al, 2013; Fig. 1) or until they reached metamorphosis. If they reached a nursery at stage 2 or higher (before metamorphosis), they were considered to settle in this area, i.e., they were not transported anymore, but the larval mortality was still applied until metamorphosis. If they attained metamorphosis outside these coastal sectors, a $0 \%$ survival was applied. This procedure of stopping movements for larvae of stages 2 or higher deteriorates the spatial resolution at settlement to mesoscale nursery areas. However, it avoids having to account for any selective tidal stream transport in the model.

\subsection{Analysis of model outputs}

The primary aim of the present large scale study was to compare patterns in larval drift and settlement success at population and metapopulation scales. The results were therefore analysed at the regional-population scale, to estimate connectivity and potential metapopulation structure and compare recruitment dynamics at settlement.

\section{Interpopulations connectivity matrix}

The individual-based trajectories allowed the estimation of connectivity from spawning to nursery areas at population scale. For each population, successful larvae settled yearly on nursery grounds were considered as a single pool and contributions of larvae coming from spawning areas of each population were calculated (Savina et al., 2010). The connectivity matrices indicate, for each regionpopulation, the proportion of larvae originating from the different spawning populations having reached a nursery of this region at the end of the simulation

\section{Sources of variability in spatio-temporal larval supply}

In the model, two factors acting at the population scale in the model impact the interannual variability of successful larval abundance: (i) the variability of the spawning peak and of the number of eggs released, (ii) larval mortality. 
Link to spawning biomass: The correlation between the number of eggs spawned and the related amount of settled larvae for each year and each region was estimated from linear models.

Interpopulation patterns and synchronicity in recruitment success: Patterns in survival from spawning to nursery areas inside each population were analysed separately. Linear models (LMs) using logittransformed survival rates as response variables were used to analyse if there were significant differences in larval survival between the different populations studied. Then correlations in annual survival rate between populations were tested to examine possible spatial correlations (also with LMs using logit-transformed survival rates).

Impact of the environment-on survival and spawning dynamics: To avoid spatial auto-correlation in observed patterns, the influence of large scale hydrographic conditions on survival success was analysed on two separate populations only, in the BoB and the EC.

The North Atlantic Oscillation (NAO) index was used as the large scale proxy for climate conditions influencing both thermal regime and hydrodynamics circulation and drift (Straile and Stenseth, 2007). The BoB and the EC time series were analysed separately: monthly values of the NAO index extracted from the NOAA National Weather Service website (NOAA, 2014) at the spawning peak period were used as covariate in correlation analysis using logit-transformed annual survival rate as response variable.

Additional analysis concerned the influence of the freshwater inputs. A significant relationship between river discharges in winter-spring and the recruitment of sole was previously demonstrated in the BoB (Le Pape et al., 2003), but also in the Mediterranean Sea (Salen-Picard et al., 2002). The influence of trophic processes during the juvenile stages has been suggested to explain this correlation (Darnaude et al., 2004; Kostecki et al., 2010); however the influence of estuarine plume on larval supply to shallow estuarine suitable nursery habitats remains to be tested. Thus the potential effect of the river flow on sole larval settlement was analysed. Two rivers were considered: the 
Vilaine River (considered as a proxy for the BoB) and the Seine river (i.e., proxy for the EC). The annual survival rate (logit-transformed, response variable) and the average river flow (covariate) from February to May (i.e., during the high river flow period influencing the period of larval drift and settlement; Le Pape et al., 2003) were used in correlation analysis. River flows were extracted from the French national database (http://www.hydro.eaufrance.fr/).

\section{Results}

\subsection{Survival Patterns}

The larval survival is low (1-5 $10^{-3}$ settling larvae per egg spawned; Table 2$)$. This low survival is due to a) larval mortality ( 99.2 to $99.8 \%$ of the total loss of larvae, Fig. 2), b) being outside nurseries at the time of the metamorphosis. The loss of larvae due to a drift out of the domain is insignificant (not shown). The abundance of larvae reaching metamorphosis in nurseries from other regions is generally extremely low (Fig. 2); from now on, the term survival will correspond to the survival of larvae in the region where the eggs were spawned. The survival rates are low in all regions (Fig. 3), with statistically significant differences between the BoB, the English Channel (WC and EC), and the NS. The BoB shows the lowest survival. In spite of a good survival at metamorphosis, the higher proportion of larvae being outside nurseries at the time of the metamorphosis (Fig. 2) leads to higher mortality. The BoB is also singled out as a region with a stronger variability in larval settlement (Table 2; Fig. 3), and by its asynchrony with the rest of the regions (Table 3).

The number of settled larvae is significantly correlated to the total number of eggs spawned in the population in the NS and in the EC and WC. However, these correlations are moderate (e.g., 29\% only in the EC; Fig. 4) and, for the BoB population, there is no correlation. 


\subsection{Connectivity between populations}

The connectivity between the four regions is very low (Fig. 5). The BoB does not receive any larvae from the outside, and the proportion of larvae settling in the WC coming from the BoB reached $2 \%$ at the maximum. The WC receives more regularly larvae coming from the EC (up to $10 \%$ ), but the opposite is not true. Only exchanges between NS and EC occur in both directions, with, a higher input from the NS to the EC (up to $41 \%$ of the larvae settling in the EC coming from the NS in 1991) than the other way around (up to $24 \%$ ). The inputs from the NS to the EC and from the EC to the WC were correlated (Fig. 5). Figures S3 and S4 provide examples of larvae distribution at the end of runs for contrasted years: 1991 and 2000 for the larvae spawned in the NS (Fig. S3) i.e., the maximum and minimum inputs of larvae from NS into EC respectively (Fig. 5); and 1995 and 2006 for the larvae spawned in the EC (Fig. S4) i.e., the minimum and maximum input of larvae from EC into NS respectively (Fig. 5). The penetration of larvae from NS into EC is maximum during the early spawning season, and tends to decrease later on (Fig. S3 and other years not shown) with slight variations between years. As a consequence, the date of the spawning peak significantly impacts this input of larvae from NS to EC $\left(\mathrm{R}^{2}=20 \%, \mathrm{p}<0.05\right)$. The pattern is less clear for the larvae spawned in EC (Fig. S4), but the penetration into NS seems to occur mid-season (e.g., April - May in 2006, Fig. S4).

\subsection{Impact of the environment on larval survival and dispersal}

\section{Environmental impacts on survival}

In EC and $W C$, the survival rate was positively correlated to the date of spawning (EC: $r^{2}=55 \%$, WC: $\mathrm{r}^{2}=26 \%, \mathrm{p}<0.05$ in both cases). The lower survival associated with warmer winter and early spawning can be associated with longer exposure to transport and mortality: early spawning lead to a longer pelagic stage, as the temperature encountered by the larvae are colder than later in the season. Both overall mortality at larval stage (Fig. 3) and transport away from the nurseries and even away from 
the local population (e.g., the year 1991 in EC; Fig. S4), are enhanced with larval stage duration, thus by an early spawning peak (Fig. S2).

The North Atlantic Oscillation (NAO) is a large scale proxy of climate conditions influencing both thermal regime and hydrodynamics in the North Atlantic. In the EC (and also in the WC) the survival rate was positively correlated to the date of spawning, without relation to the NAO. On the contrary, the NAO index in February had a positive impact on survival in the BoB (Fig. 6): positive NAO increased the proportion of larvae reaching nursery before metamorphosis in the BoB.

No impacts of river flows could be found on the larval survival rates in any of the two studied regions.

\section{Environmental impacts on larval exchanges between populations}

No influence of the tested environmental proxies (river flow, NAO index) on connectivity was detected.

\section{Discussion}

In the present study, we built upon previous knowledge and preliminary modelling approaches to simulate sole larval supply in coastal and estuarine nursery areas on a wide spatial scale covering four fished sole stocks-populations, from the BoB to the NS, over a long period of time (1982-2007). If similar modelling approaches were already developed on several flatfish populations (e.g., Sentchev and Korotenko, 2005; Bolle et al., 2009; Lacroix et al., 2013), this is to our best knowledge the first one with such a wide spatiotemporal scale. From the analysis of the model outputs, patterns of larval settlement success and dispersal, and sensitivity to climate-driven variability in hydrography were assessed at population scale, and the consequences on recruitment dynamics and metapopulation structure were analysed. 


\subsection{Data caveats linked to process errors in larval drift individual based models}

In this study, we used an individual-based larval transport model coupled online to a hydrodynamic model. This modelling approach is far from being the first contribution of numerical simulation models to investigate the processes underlying the variability of fish recruitment (Miller 2007; Hinrichsen et al., 2011). However, it is original for both its large spatial and temporal scales, which allowed us to assess metapopulations connectivity at larval stages, as well as the interannual and interpopulation variability of larval recruitment dynamics.

This was possible to do for flatfish as their life cycle is characterized by a metamorphosis to benthic life (Gibson, 2005) ending the pelagic life stage. From metamorphosis, juveniles swim to shallow adjacent nursery grounds (Ramzi et al., 2001ab; Fox et al., 2006), using selective tidal stream transport (Rijnsdorp et al., 1985; Bergman et al., 1989; Grioche et al., 2000) enhancing their recruitment success in coastal nursery grounds (Ramzi et al., 2001b; Fox et al., 2006; Cowen et al, 2006). This behaviour maintains larvae over nursery sectors once areas are reached by stage $2+$ larvae, which drastically simplifies the end of simulations under realistic hypotheses. Indeed, estimating larval supply at the scale of nurseries did not require knowing the exact final destination of larvae but only the nursery sector where settlement occurred (i.e., before selective tidal stream). The use of a quite large hydrodynamical model mesh grid (i.e., $4 \mathrm{~km}$ ) allowed us to carry out simulations over several decades on several thousands of $\mathrm{km}$ range of latitude, at a metapopulation scale.

The accuracy of the hydrodynamics model Mars 3D (Lazure and Dumas, 2008) to simulate currents and hydrology from the BoB (Lazure et al. 2009) to the NS (Bailly du Bois and Dumas, 2005) was previously assessed. In the seminal model on restricted spatial (i.e., the EC) and temporal scales (Rochette et al., 2012), the northern boundaries close to the northern limit of the EC led to caveats on the connectivity from EC to the NS population. The current model implementation (extended to a 
dramatically wider scale) led to an increase in the reliability of simulation outputs, although they should still be considered as a first approach in the case of the southern NS (closer to the model boundaries).

The higher input of larvae from the NS towards the EC than from the EC to the NS appeared counterintuitive as it is generally accepted that Atlantic water flows into the North Sea through the English Channel on an annual basis (e.g., Bailly du Bois and Dumas, 2005 and ref. therein). However, the transport of sole larvae occurs only during a restricted part of the year; in the case of the EC and NS, most of the larvae are transported between the julian days 100 and 200 (see Fig. S2), during which the annual east drift into the north Atlantic is limited (Straile and Stenseth 2007), as its consequences on the hydrodynamics across the English Channel. It is also important to keep in mind that the occurrence of larvae spawned in region A and settling in region B is not only the result of the transport occurring between those two regions, but also of the distribution of the nursery areas along the larvae trajectories (high probability to reach a suitable nursery grounds for larvae entering the EC from the NC; Figures S3 and S4).

Accordingly, the representation of the spatiotemporal patterns in spawning dynamics appears realistic. The relationship between the timing of spawning and the sea temperature was parametrized from previous knowledge (Rochette et al., 2012; Fincham et al., 2013). The monthly quantitative maps of spawning and total annual amount of eggs in each populations were extended from Rochette et al. (2012) from available data on eggs surveys (ICES, 1992) and spawning stock biomass estimates from stock assessment groups (ICES, 2014ab). The parental influence on early life history traits is here assessed from a conversion of annual spawning biomass in a number of eggs (Rochette et al., 2012). This roughly assessed conversion can lead to caveats in estimation of reproductive success for marine fish (Trippel et al., 2005; Wright and Trippel 2009), especially as it 
does not account for fishing induced evolution in sole populations (Mollet et al., 2007). However, general patterns in spawning dynamics are represented from this approach.

The larval IBM considers only hydrodynamic drivers; i.e., currents and temperature, leading to significant process error in parametrization of larval survival. For instance, larval food availabilty/deprivation and related behaviour and survival (Daewel et al., 2011), such as the variability in predation on larvae, are not accounted for in the IBM. This approach thus remains an approximation, excluding many trophic related sources of variability in larval survival (Moran et al, 2011; Gallego et al 2012; Peck et Hufnagl 2012). However, it allows for the study of the combined effects on recruitment success of hydrodynamics (on the variability in transport of eggs and larvae (Bolle et al., 2009)) and of the spawning biomass (Rochette et al., 2012).

\subsection{High segregation at larval stages}

The previous smaller space-time scale approach (Rochette et al., 2012) showed limited larval dispersal inside one single population, with spawning areas feeding adjacent coastal and estuarine nursery grounds without significant exchanges with other sub-regions of the EC. At the population scale, the connectivity is even more limited and we observed very low exchanges between the different populations, with the single exception of the exchanges between the NS and the EC which, in the case of this study appear moderate to quite large ( $>40 \%$ of external larvae in the EC for some years). Previous studies (Savina et al, 2010, Lacroix et al, 2013) have identified larval exchanges between EC and NS, but with a higher input from EC towards NS than the other way around. They are difficult to compare with the results presented here however, as they describe the exchanges between the French coasts of northern EC and the Belgian coasts, while our results describe the exchanges between the whole EC and the whole NS. Zooming in our results, it appears that the 
inputs of larvae from the NS to the EC are mostly driven by what happens along the coasts of England.

In coastal marine organisms, long planktonic larval stages enable large dispersal (Pringle et al, 2014).

The duration of the larval stages is lower than two months in the different populations of common sole, from the Mediterranean Sea (Morat et al., 2014) to the BoB and the NS (Rochette et al., 2012). Considering this relatively short duration of pelagic life for a long living fish, especially with regards to other flatfish such as common plaice (Nash and Geffen, 2012), the connectivity at larval stage is moderate (Gerber et al, 2014) and lead to very low exchanges of common sole larvae between populations.

These segregation patterns are reinforced by natural barriers between populations: areas of pebbles and rocks forms large gaps between the EC, WC and BoB soft-bottomed spawning grounds (Eastwood et al., 2001).

Associated with very moderate movements of sole at the juvenile (Coggan and Dando, 1988; Anon., 1989; Le Pape and Cognez, in press) and adult (Kotthaus, 1963; Anon., 1965; Burt and Millner, 2008) stages, this very low connectivity at the larval stage suggests a high level of segregation between populations of sole, from the BoB to the NS. This segregation is partly confirmed from population genetics, with observed genetic structure segregating the BoB from the English Channel (WC and EC) and North Sea complex (Cuveliers et al., 2012). However, to our best knowledge, no genetic segregation has been demonstrated at a lower scale.

\subsection{Common patterns and discrepancies between populations linked to life history}

The larval survival is generally very low $\left(10^{-3}\right)$, and within the order of magnitude suggested in Le Pape and Bonhommeau (2015). However, estimates of survival are especially sensitive to the larval daily mortality rate (Rochette et al., 2012) and have to be considered with caution. Although the 
survival rate depends on this poorly known parameter, the interannual fluctuations of the larval supply in the different populations were not sensitive to change in larval mortality. Larval mortality appeared as a scale factor (Rochette et al., 2012) thus spatial patterns and influence of both hydrodynamics and spawning biomass on larval recruitment success can be derived from relative variability in the survival and the amount of settled larvae.

The eggs and larvae mortality (linked to the duration of those stages) corresponds to more than $98 \%$ of the loss of larvae (Fig. 2). The remaining loss is due to metamorphosis away from suitable areas, leading to a moderate decrease in larval survival rate.

However, spatial contrasts suggest a different recruitment dynamic in the BoB compared to the English Channel (EC and WC)-NS complex: a more variable survival rate, together with a higher level of metamorphosis away from nursery grounds lead to the absence of correlation between the number of eggs spawned and the number of settled larvae. We explain these results by the different spatial configuration of the spawning grounds and nurseries in the BoB compared to the English Channel and NS. In the BoB, the spawning grounds are located offshore (Arbault et al., 1986). The eggs and larvae have to be advected towards the coast with extremely variable outcomes and a low rate of success, independently of the amount of eggs spawned. In the English Channel (EC and WC) and NC, spawning grounds are closer to the nurseries (Eastwood et al., 2001). Metamorphosis outside nursery areas is limited; larvae remain in the vicinity of the nurseries once they are spawned near the coast (Grioche et al., 2001). Such differences between populations in the distance and level of connection between spawning and nursery grounds have been observed for other flatfish species such as plaice in the same area (Fox et al. 2006, Bolle et al., 2009) but also winter flounder in the North West Atlantic (Buckley et al., 2008; Wilber et al., 2013). 


\subsection{Environmental factors influencing larval survival}

The abundance of settled larvae related only moderately to the amount of spawned eggs, and even not at all in the case of the BoB. During this quite short ( $<2$ months) pelagic stage, the variability in larval survival hampers the identification of spawning products-larval recruitment relationships. This large variability, together with the additional stochastic factors linked to trophic processes at larval stages (Daewel et al., 2011; Moran et al, 2011; Peck et Hufnagl 2012), and the post settlement regulation linked to density dependent processes in nursery habitats (Iles and Beverton, 2000; Brown et al, 2005; Le Pape and Bonhommeau, 2015) blur stock recruitment relationships for sole populations, and more generally for flatfish (Iles, 1994; Archambault et al., 2014; Cury et al., 2014).

For two separate populations, in the EC and the BoB (i.e., excluding autocorrelation in the English Channel-North Sea metapopulation complex), the present modelling approach suggests that different environmental processes control the larval recruitment. In the EC, shallow coastal spawning grounds (ICES, 1992; Eastwood et al., 2001; Grioche et al, 2001) allow for relatively low loss of larvae outside nursery areas at metamorphosis, thus moderate variability in survival rate, but for a significant influence of temperature on the spawning period (Fincham et al., 2013). However, the spawning period in the EC (spawning peak in April-May (van Beek, 1988; Rochette et al., 2012)) leads to a larval drift mainly focused in late spring. At this period, the NAO index, appropriate to synthetize winter conditions (Straile and Stenseth, 2007), is not accurately representing climate and hydrography conditions. Even if the influence of hydrodynamics on larval survival appears relatively limited, further analysis would be needed to analyse the potential influence of hydrodynamics on annual larval survival from the WC to the NS. On the contrary, in the BoB, the spawning grounds are offshore (Arbault et al., 1986) and quite deep which lead to a stability in the spawning process (Koutsikopoulos et al., 1991). These deep and less coastal spawning grounds lead to higher distance from spawning to nursery grounds and to higher stochasticity in larval drift 
toward suitable nursery grounds, with important effects of hydrodynamics on larval survival. Positive NAO induces western currents in late winter (Straile and Stenseth, 2007) in the BoB (Puillat et al 2004), and therefore enhanced drift of sole larvae to coastal nursery grounds (located on the western coast; Fig. 1) before metamorphosis. Considering driving factors of larval survival in both BoB and EC thus leads to conclude that the impact of driving factors are not spatially consistent (Lacroix et al., 2013) at the population scale.

For the two studied populations (BoB and EC), no detected effect of river flow on larvae survival rate was shown, whereas an effect of river flow on recruitment success at juvenile stages was previously demonstrated in the BoB (Le Pape et al., 2003abc). This tends to confirm that the effect of river flow on juvenile abundance is due to its effects on the quality of the nursery habitat (i.e., supply of organic matter linked to freshwater input in their food supply chain; Darnaude et al., 2004; Leakey et al, 2008; Kostecki et al., 2010) rather than on the amount of settled larvae.

\section{Acknowledgements}

This work was partly funded by the European Community's Seventh Framework Programme (FP7/ 2007-2013) under Grant Agreement No. 266445 for the project Vectors of Change in Oceans and Seas Marine Life, Impact on Economic Sectors (VECTORS). We would like to thank Sophie Pasquier for editing the references, as well as four anonymous reviewers for their constructive comments on our manuscript.

\section{References}

Amara, R., Lagardère, F., 1995. Taille et âge au début de la métamorphose chez la sole (Solea solea (L.)) du golfe de Gascogne. ICES J. Mar. Sci. 52, 247-256. 
Anon., 1965. Report of the working group on sole. ICES Coop. Res. Rep. 5, 1-126.

Anon., 1989. Report of the ad hoc working group on juvenile sole tagging. Page 34. Ostende, 10-12 March 1987.

Arbault,S., Camus, P., Le Bec, C., 1986. Estimation du stock de sole (Solea vulgaris, Quensel 1806) dans le Golfe de Gascogne à partir de la production d'oeufs. J. Appl. Ichthyol. 4, 145-156.

Archambault, B., Le Pape, O., Bousquet, N., Rivot, E., 2014. Density-dependence can be revealed by modelling the variance in the stock recruitment process: an application to flatfish. ICES J. Mar. Sci. 8, 2127-2140.

Ayata, S.D., Lazure, P., Thiebaut E., 2010. How does connectivity between populations mediate range limits of marine invertebrates? A case study of larval dispersal between Bay of Biscay and English Channel (North East Atlantic). Prog. Oceanogr. 87, 18-36.

Bailly du Bois P.B., Dumas, F. (2005) Fast hydrodynamic model for medium- and long-term dispersion in seawater in the English Channel and southern North Sea, qualitative and quantitative validation by radionuclide tracers. Ocean Modelling 9 (2005) 169-210

Bergman, M.J.N., Van Der Veer, H.W., Stam, A., Zuideman, D., 1989. Transport mechanisms of larval plaice (Pleuronectes platessa L.) from the coastal zone into the Wadden Sea nursery area. P.v. Réun. Cons. int. Explor. Mer. 191, 43-49.

Blaxter, J.H.S., 1969. Visual Thresholds and Spectral Sensitivity of Flatfish Larvae. J. Exp. Biol. 51, 221-230.

Bolle, L., Dickey-Collas, M., van Beek, J.K.L., Erftemeijet, P.L.A., Witte, J.I.J., van der Veer, H.W., Rijnsdorp, A.D., 2009. Variability in transport of fish eggs and larvae. III. Effects of hydrodynamics and larval behaviour on recruitment in plaice. Mar. Ecol. Prog. Ser. 390, 195-211. 
Brown, C.A., Jackson, G.A., Holt, S.A., Holt, G.J., 2005. Spatial and temporal patterns in modeled particle transport to estuarine habitat with comparisons to larval fish settlement patterns. Estuar. Coast. Shelf Sci. 64(1), 33-46.

Buckley, L., Collie, J., Kaplan, LAE, Crivello J. (2008). Winter Flounder Larval Genetic Population Structure in Narragansett Bay, RI: Recruitment to Juvenile Young-of-the-Year. Estuaries and Coasts, 31,(4): 745-754.

Burt, G.J., Millner, R.S., 2008. Movements of sole in the southern North Sea and eastern English Channel from tagging studies (1955-2004). Sci.Ser.Tech.Rep. 44, Cefas, Lowestoft.

Coggan, R.A., Dando, P.R., 1988. Movements of juvenile Dover sole, Solea solea (L.), in the Tamar Estuary, South-western England. J.Fish Biol. 33, 177-184.

Cowen, R.K., Paris, C.B., Srinivasan, A., 2006. Scaling connectivity in marine populations. Science 311, $522-527$.

Cury, P.M., Fromentin, J.M., Figuet, S., Bonhommeau, S., 2014. Resolving Hjort's Dilemma: How Is recruitment related to spawning stock biomass in marine fish? Oceanogr. 27(4), 42-47.

Cuveliers, E., Larmuseau, M., Hellemans, B., Verherstraeten, S.,Volckaert, F., Maes, G., 2012. Multimarker estimate of genetic connectivity of sole (Solea solea) in the North-East Atlantic Ocean. Mar. Biol. 159(6), 1239-1253.

Daewel, U., Peck, M., Shrum, C., 2011. Life history strategy and impacts of environmental variability on early life stages of two marine fishes in the North Sea: an individual based modelling approach. Can. J. Fish. Aquat. Sci. 68, 426-443.

Darnaude, A.M., Salen-Picard, C., Polunin, N.V.C., Harmelin-Vivien, M.L., 2004. Trophodynamic linkage between river runoff and coastal fishery yield elucidated by stable isotope data in the Gulf of Lions (NW Mediterranean). Oecologia 138(3), 325-332. 
Dorel, D., Koutsikopoulos, C., Desaunay, Y., Marchand, J., 1991. Seasonal distribution of young sole (Solea solea (L.)) in the nursery ground of the Bay of Vilaine (northern Bay of Biscay). Neth. J. Sea Res. 27, 297-306.

Eastwood, P.D., Meaden, G.J., Grioche, A., 2001. Modelling spatial variations in spawning habitat suitability for the sole Solea solea using regression quantiles and GIS procedures. Mar. Ecol. Prog. Ser. 224, 251-266.

Fincham, J.I., Rijnsdorp, A.D., Engelhard, G.H., 2013. Shifts in the timing of spawning in sole linked to warming sea temperature. J. Sea Res. 75, 69-76.

Fox, C.J., Mccloghrie, P., Young, E.F., Nash, R.D.M., 2006. The importance of individual behaviour for successful settlement of juvenile plaice (Pleuronectes platessa L.): a modelling and field study in the eastern Irish Sea. Fish. Oceanogr. 15, 301-313.

Gallego, A., North, E., Houde, E.D., 2012. Understanding and quantifying mortality in pelagic, early life stages of marine organisms - Old challenges and new perspectives. J. Marine Syst. 93, 1-3.

Gerber, L.R., Del Mar Mancha-Cisneros, M., O'Connor` M.I., Selig, E.R., 2014. Climate change impacts on connectivity in the ocean: implications for conservation. Ecosphere 5(3), 1-18.

Gibson, R.N., 2005. Flatfishes : biology and exploitation. Blackwell Publishing. Oxford, UK Grioche, A., Harlay, X., Koubbi, P., Fraga Lago, L., 2000. Vertical migrations of fish larvae: Eulerian and Lagragian observations in the Eastern English Channel. J. Plankton Res. 22(10), 1813-1828.

Grioche, A., Koubbi, P., Harlay, X., Sautour,B., 2001. Sole larval distribution (Solea solea) in the esatern English Channel and Southern Bight of the North Sea. J. Mar. Biol. Ass. UK 81, 673-678.

Hinrichsen, H.H., Dickey-Collas, M., Huret, M., Pech, M.,Vikebo, F.B., 2011. Evaluating the suitability of coupled biophysical models for fishery management. ICES j. Mar Sci. 68(7), 1478-1487.

Horwood, J., 1993. The bristol Channel Sole (Solea solea (L.)) : A fishery case study. Adv. Mar. Biol. 29, 215-367. 
Houde, E.D., 2008. Emerging from Hjort's shadow. J. Northw. Atl. Fish. Sci. 41, 53-70.

Huret, M., Petitgas, P., Woillez, M., 2010. Dispersal kernels and their drivers captured with a hydrodynamic model and spatial indices: a case study on anchovy (Engraulis encrasicolus) early life stages in the Bay of Biscay. Prog. Oceanogr. 87, 6-17.

ICES, 1992. Report of the study group on the fecundity of sole and plaice in sub-areas IV, VII, and VIII. ICES, CM 1992/G: 16

ICES, 2014a. Report of the Working Group on the Assessment of Demersal Stocks in the North Sea and Skagerrak (WGNSSK), ICES Headquarters, Copenhagen. ICES Document CM 2014/ACOM:13. (1530 pp).

ICES, 2014b. Report of the Working Group for the Bay of Biscay and the Iberian waters Ecoregion, 713 May 2014, Lisbon, Portugal, ICES Document CM 2014/ACOM:11. 748 pp.

Iles, T.C., 1994. A review of stock-recruitment relationships with reference to flatfish populations. Neth. J. Sea Res. 32(3-4), 399-420.

Iles, T.C., Beverton, J.H., 2000. The concentration hypothesis: the statistical evidence. ICES J. Mar. Sci. $57,216-227$.

Johnson, D.W., 2007. Habitat complexity modifies post-settlement mortality and recruitment dynamics of marine fish. Ecology 88, 1716-1725.

Juanes, F., 2007. Role of habitat in mediating mortality during the post-settlement transition phase of temperate marine fishes. J. Fish. Biol. 70, 661-677.

Kostecki, C., Le Loc'h, F., Roussel, J.M., Desroy, N., Huteau, D., Le Bris, H., Le Pape, O., 2010. Dynamics of an estuarine nursery ground: the spatio-temporal relationship between the river flow and the food web of the juvenile common sole (Solea solea) as revealed by stable isotopes analysis. J. Sea Res. 64, 54-60. 
Kotthaus, A. 1963. Tagging experiments with the North Sea sole (Solea solea) in 1959 and 1960. Spec.Publ. Int. Commn. NW. Atlan. Fish, 123-129.

Koutsikopoulos, C., Fortier, L., Gagne, J.A., 1991. Cross-well dispersion of dover sole (Solea solea (L.)) eggs and larvae in Biscay Bay and recruitment to inshore nurseries. J. Plankton Res. 13, 923-945. Lacroix, G., Maes, G.E., Bolle, L.J., Volckaert, F.A.M. (2013) Modelling dispersal dynamics of the early life stages of a marine flatfish (Solea solea L.). J.Sea Res. 84, 13-25.

Lazure, P., Dumas, F., 2008. An external-internal mode coupling for a 3D hydrodynamical model for applications at regional scale (MARS). Adv. Water Resour. 31(2), 233-250.

Lazure P., Garnier V., Dumas F., Herry C., Chifflet M. (2009) : Development of a hydrodynamic model of the Bay of Biscay. Validation of hydrology. Cont. Shelf. Res. 29(8): 985-997

Le Pape, O., Chauvet, F., Desaunay, Y., Guerault, D., 2003. Relationship between interannual variations of the river plume and the extent of nursery grounds for the common sole (Solea solea, L.) in Vilaine Bay. Effects on recruitment variability. J. Sea Res. 50, 177-185.

Le Pape, O., Chauvet, F., Mahevas, S., Lazure, P., Guerault, D., Desaunay, Y., 2003. Quantitative description of habitat suitability for the juvenile common sole (Solea solea, L.) in the Bay of Biscay (France) and the contribution of different habitats to the adult population. J. Sea Res. 50, 139-149.

Le Pape, O., Holley, J., Guerault, D., Desaunay, Y., 2003. Quality of coastal and estuarine fish habitats: estimations based on the size of juvenile common sole (Solea solea L.). Estuar. Coast. Shelf Sci. 58, 793-803.

Le Pape, O., Bonhommeau, S., 2015. The food limitation hypothesis for juvenile marine. Fish Fish. 16(3), 373-398.

Le Pape, O., Cognez, N., 2015. The range of juvenile movements of estuarine and coastal nursery dependent flatfishes: estimation from a meta-analytical approach. Journal of Sea Research (in press). 
Leakey, C.D.B., Attril, M., Jennings, S., Fitzsimons M.F. 2008. Retrospective quantification of estuarine feeding activity by coastally caught marine fishes. J.Sea R. 60, 210-224.

Levin, P.S., Stunz, G.W., 2005. Habitat triage for exploited fishes: can we identify essential fish habitat? Estuar. Coast. Shelf Sci. 64, 70-78.

Loots, C., Vaz, S., Planque, B., Koubbi, P., 2009. What controls the spatial distribution of the North Sea plaice spawning population? Confronting ecological hypotheses through a model selection framework. ICES J. Mar. Sci. 67, 244-257.

Lund, I., Steenfeldt, S.J., Suhr, K.I., Hansen,B.W., 2008. A comparison of fatty acid composition and quality aspects of eggs and larvae from cultured and wild broodstock of common sole (Solea solea L.). Aquacult. Nutr. 14(6), 544-555.

Matheron, G., 1963. Principles of geostatistics. Econ. Geol. 5, 1246-1266.

Michel, S., Treguier, A.M., Vandermeirsch, F., 2009. Temperature variability in the Bay of Biscay during the past 40 years, from an in situ analysis and a 3D global simulation. Cont. Shelf Res. 29, 1070-1087.

Miller, T.J., 2007. Contribution of individual-based coupled physical-biological models to understanding recruitment in marine fish populations. Mar. Ecol. Prog. Ser. 347, 127-138.

Mollet, F.M., Kraak, S.B.M., Rijnsdorp, A.D., 2007. Fisheries induced evolutionary changes in maturation reaction norms in North Sea Sole Solea solea. Mar. Ecol. Prog. Ser. 351, 189-199.

Moran, D., Smith, C.K., Lee, P.S., Pether, S.J., 2011. Mortality structures population size characteristics of juvenile yellowtail kingfish Serila lalandi reared at different densities. Aquat. Biol. 11, 229-238.

Morat, F., Letourneur, Y., Blamart, D., Pécheyran, C., Darnaude, A.M., Harmelin-Vivien, M., 2014. Offshore-onshore linkages in the larval life history of sole in the gulf of Lions (NW-Mediterranean). Estuar. Coast. Shelf Sci. 149, 194-202.

NOAA,2014. //www.cpc.ncep.noaa.gov/products/precip/CWlink/pna/norm.nao.monthly. 
b5001.current.ascii.table

Nash, R.D.M., Geffen, A.J., 2012. Mortality through the early life-history of fish: What can we learn from European plaice (Pleuronectes platessa L.)? J. Marine Syst. 93, 58-68.

Peck, M.A. and Hufnagl, M., 2012. Can IBMs tell us why most larvae die in the sea? Model sensitivities and scenarios reveal research needs. J. Marine Sys. 93, 77-93.

Petitgas, P., Magri, S., Lazure, P., 2006. One-dimensional biophysical modelling of fish egg vertical distributions in shelf seas. Fish. Oceanogr. 15, 413-428. doi:10.1111/j.1365-2419.2006.00409.x

Pringle, J.M., Byers, J.E., Pappalardo, P., Wares, J.P., Marshall, D., 2014. Circulation constrains the evolution of larval development modes and life histories in the coastal ocean. Ecology 95(4), 10221032.

Puillat, I., Lazure, P., Jégou, A.M., Lampert, L., Miller, P.I., 2004. Hydrographical variability on the French continental shelf in the Bauy of Biscay, during the 1990s. Cont. Shelf Res. 24(10), 1143-1163.

Ramzi, A., Arino, O., Koutsikopoulos, C., Boussouar, A., Lazure,P., 2001. Modelling and numerical simulations of larval migration of the sole (Solea solea (L.)) of the Bay of Biscay. Part 1: modelling. Oceanol. Acta 24(2), 101-112.

Ramzi, A., Arino, O., Koutsikopoulos, C., Boussouar, A., Lazure,P., 2001. Modelling and numerical simulations of larval migration of the sole (Solea solea (L.)) of the Bay of Biscay. Part 2: numerical simulations. . Oceanol. Acta 24(2), 113-124.

Rijnsdorp, A.D., Van Stralen, M., Van der Veer, H.W., 1985. Selective tidal transport of north sea plaice larvae (Pleuronectes platessa) in coastal nursery areas. T. Am. Fish. Soc. 114, 461-470.

Rijnsdorp, A.D., Vingerhoed, B., 1994. The ecological significance of geographical and seasonal differences in egg size in sole Solea solea (L.). Neth. J. Sea Res. 32, 255-270.

Rochette, S., Huret, M., Rivot, E., Le Pape, O., 2012. Coupling hydrodynamic and individual-based models to simulate long-term larval supply to coastal nursery areas. Fish. Oceanogr. 21(4), 229-242. 
Riou P., Le Pape, O., Rogers, S.I., 2001. Relative contributions of different sole and plaice nurseries to the adult population in the Eastern Channel: application of a combined method using generalized linear models and a geographic information system. Aquat. Living Resour. 14, 125-135.

Ryland, S.S., 1963. The swimming speeds of plaice larvae. J. Exp. Biol. 40, 285-299.

Saha, S., Moorthi, S., Pan, H., Wu, X., Wang, J., Nadiga, S., Tripp, P., Kistler, R., Woollen, J., Behringer, D., Liu, H., Stokes, D., Grumbine, R., Gayno, G., Wang, J., Hou, Y., Chuang, H., Juang, H. H., Sela, J., Iredell, M., Treadon, R., Kleist, D., Van Delst, P., Keyser, D., Derber, J., Ek, M., Meng, J., Wei, H., Yang, R., Lord, S., van den Dool, H., Kumar, A., Wang, W., Long, C., Chelliah, M., Xue, Y., Huang, B., Schemm, J., Ebisuzaki, W., Lin, R., Xie, P., Chen, M., Zhou, S., Higgins, W., Zou, C., Liu, Q., Chen, Y., Han, Y., Cucurull, L., Reynolds, R. W., Rutledge, G., Goldberg, M. 2010. NCEP Climate Forecast System Reanalysis (CFSR) 6-hourly Products, January 1979 to December 2010. Research Data Archive at the National Center for Atmospheric Research, Computational and Information Systems Laboratory.

http://dx.doi.org/10.5065/D69K487J. Accessedt 01/04/2012.

Salen-Picard, C., Darnaude, A.M., Arlhac, D., Harmelin-Vivien, M.L., 2002. Fluctuations of macrobenthic populations: a link between climate-driven run-off and sole fishery yields in the Gulf of Lions. Oecologia 133, 380-388.

Savina, M., Lacroix, G., Ruddick, K., 2010. Modelling the transport of common sole larvae in the Southern North Sea: Influence of hydrodynamics and larval vertical movements. J. Marine Sys. 81, $86-98$.

Sentchev, A., Korotenko, K., 2005. Dispersion processes and transport pattern in the ROFI system of the eastern English Channel derived from a particle-tracking model. Cont. Shelf Res. 25, 2294-2308. Sentchev, A., Korotenko, K., 2007. Modelling distribution of flounder larvae in the eastern English Channel: sensitivity to physical forcing and biological behaviour. Mar. Ecol. Prog. Ser. 347, 233-245. 
Straile, D., Stenseth, N.C., 2007. The north Atlantic Oscillation and ecology: links between historical time-series, and lessons regarding future climate warming. Climate Res. 34(3), 259-262.

Trippel, E.A., Kraus, G., Köster, F.W., 2005. Maternal and paternal influences on early life history traits and processes of Baltic cod Gadus morhua . Mar. Ecol., Prog. Ser. 303, 259-267.van Beek, F. A., 1988. On the growth of sole in the North Sea. ICES, CM 1988/G:24 (23pp).

Van der Land, M.A., 1991. Distribution of flatfish eggs in the 1989 egg surveys in the Southeastern North Sea, and mortality of plaice and sole eggs. Neth. J. Sea Res. 27(3-4), 277-286.

Van der Veer, H.W., Geffen, A., Witte, J.I.J., 2000. Exceptionnaly strong year classes in plaice Pleuronectes platessa: are they generated during the pelagic stage only, or also in the juvenile stage? Mar. Ecol. Prog. Ser. 199, 255-262.

Vert-Pre, K., Amoroso, RO., Jensen, O.P., Hilborn, R., 2013. Frequency and intensity of productivity regime shifts in marine fish stocks. P. Natl. Acad. Sci. USA 110 (5), 1779-1784.

Wheeler, A., 1978. Key to the fishes of northern Europe. Frederick Warne \& Co Ltd, London, UK (380 pp).

Wilber, D.H., Wilber , Clarke, D.G., Gallo, J., Alcoba, C.J., Dilorenzo,A.M., Zappala, S.E., 2013. Identification of Winter Flounder (Pseudopleuronectes americanus) Estuarine Spawning Habitat and Factors Influencing Egg and Larval Distributions. Estuaries and Coasts. 36(6 $1304-1318$.

Wright, P.J., Trippel, E.A., 2009. Fishery-induced demographic changes in the timing of spawning: consequences for reproductive success. Fish Fish. 10, 283-304. 


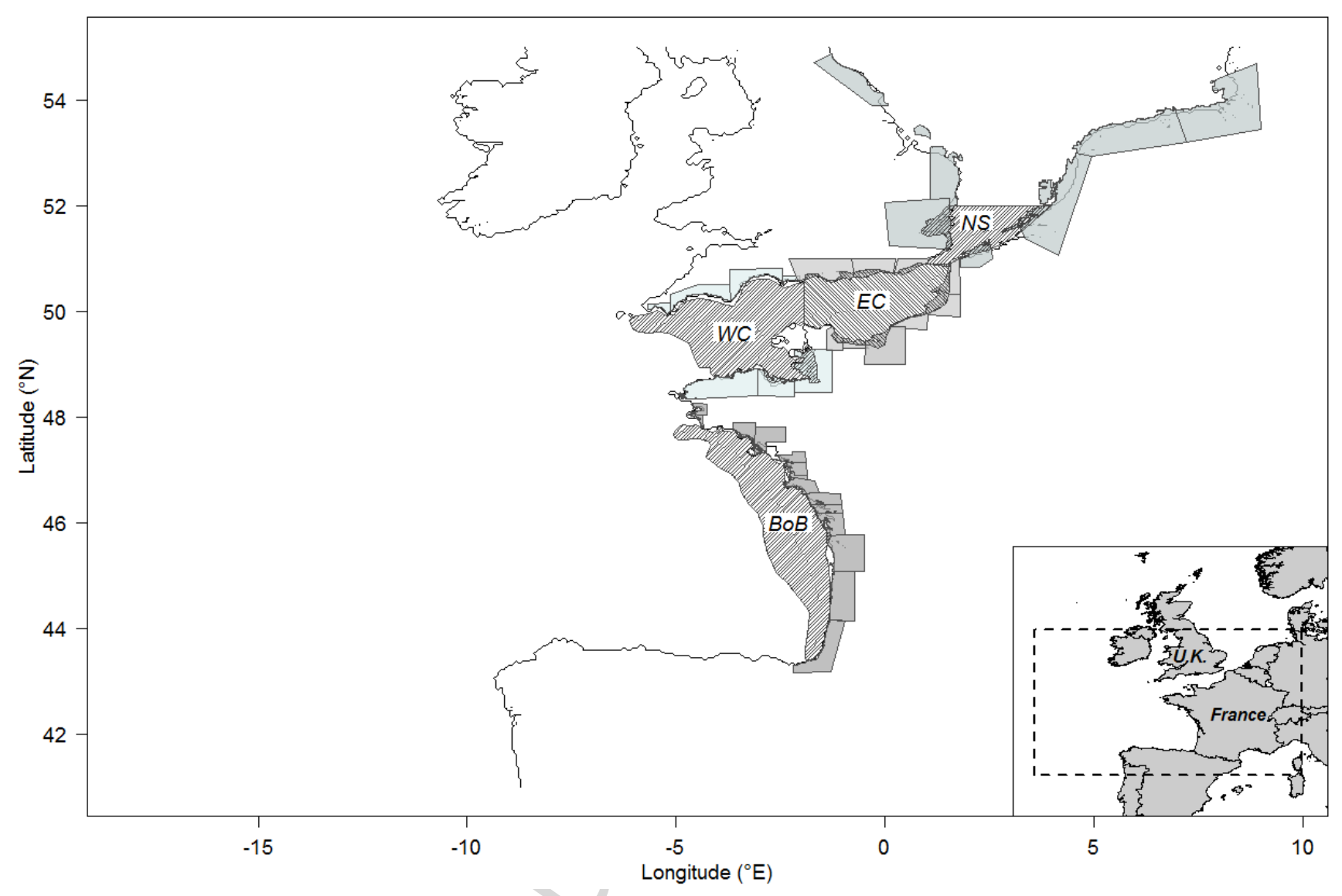

Figure 1 


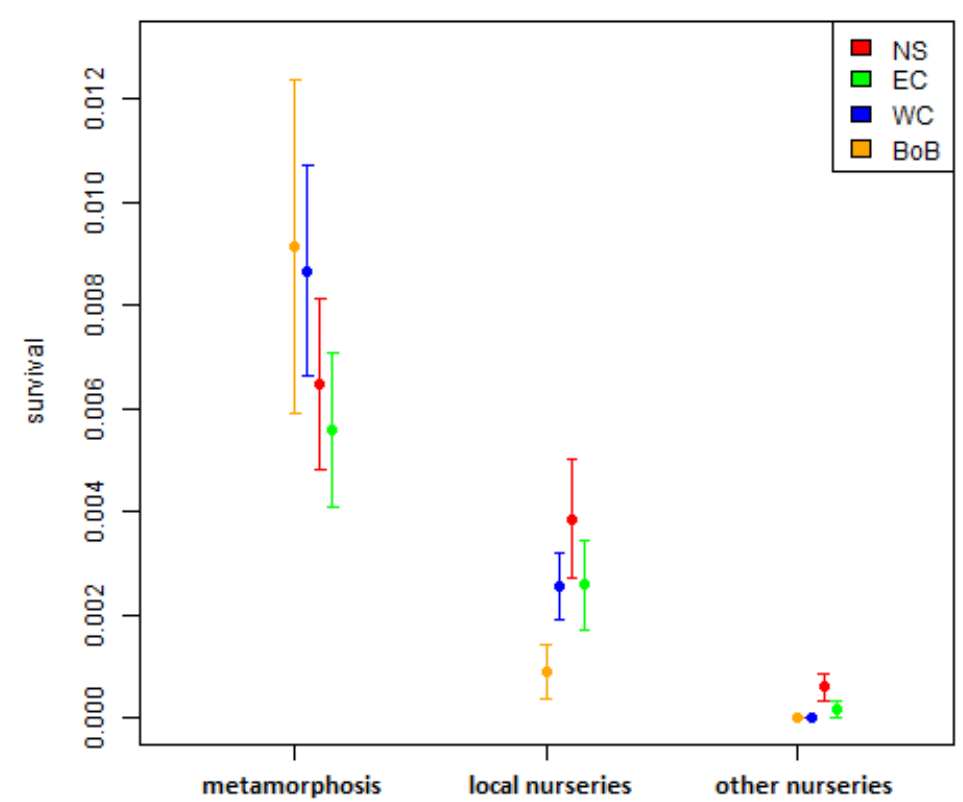

Figure 2 


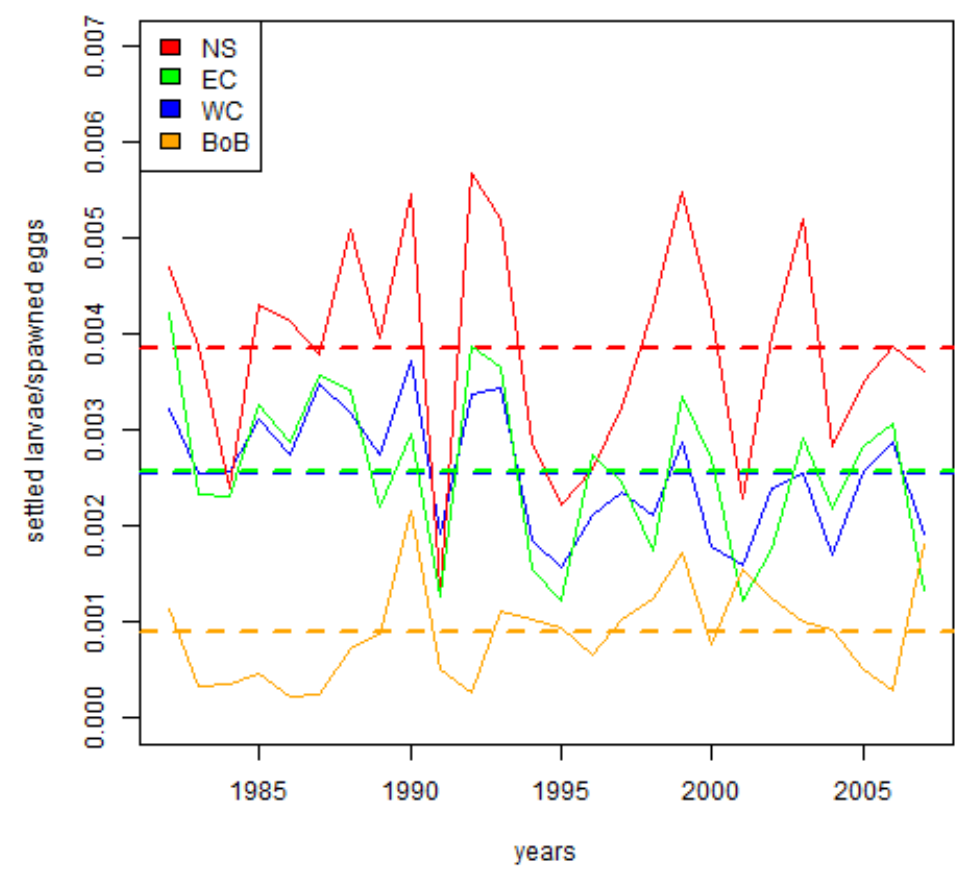

Figure 3 

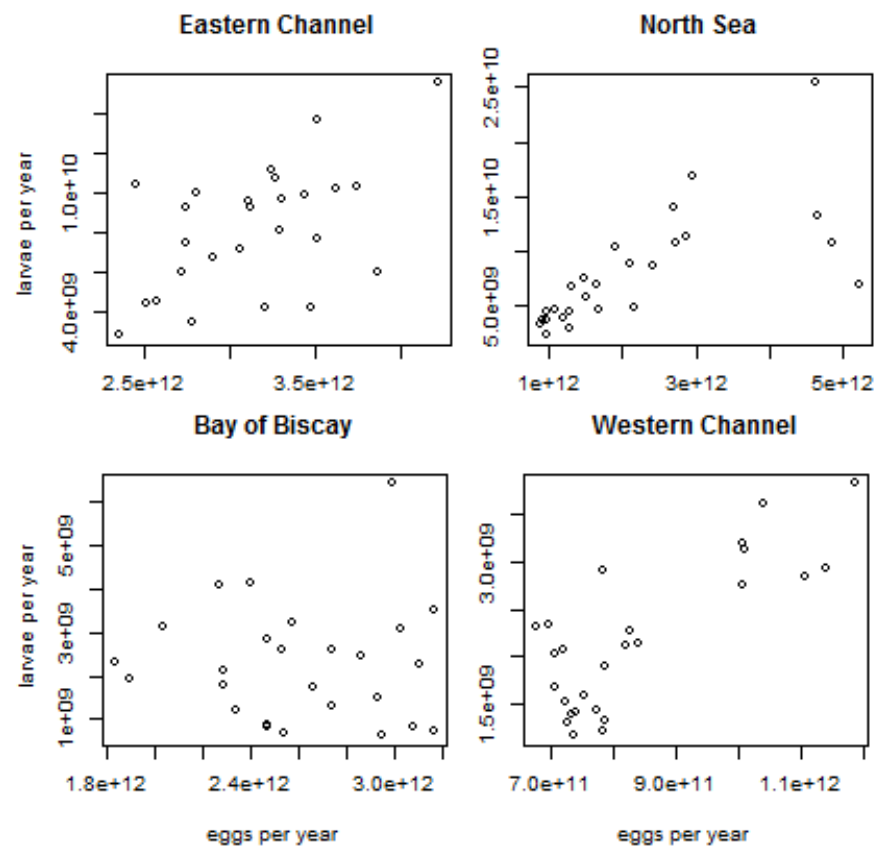

Figure 4 

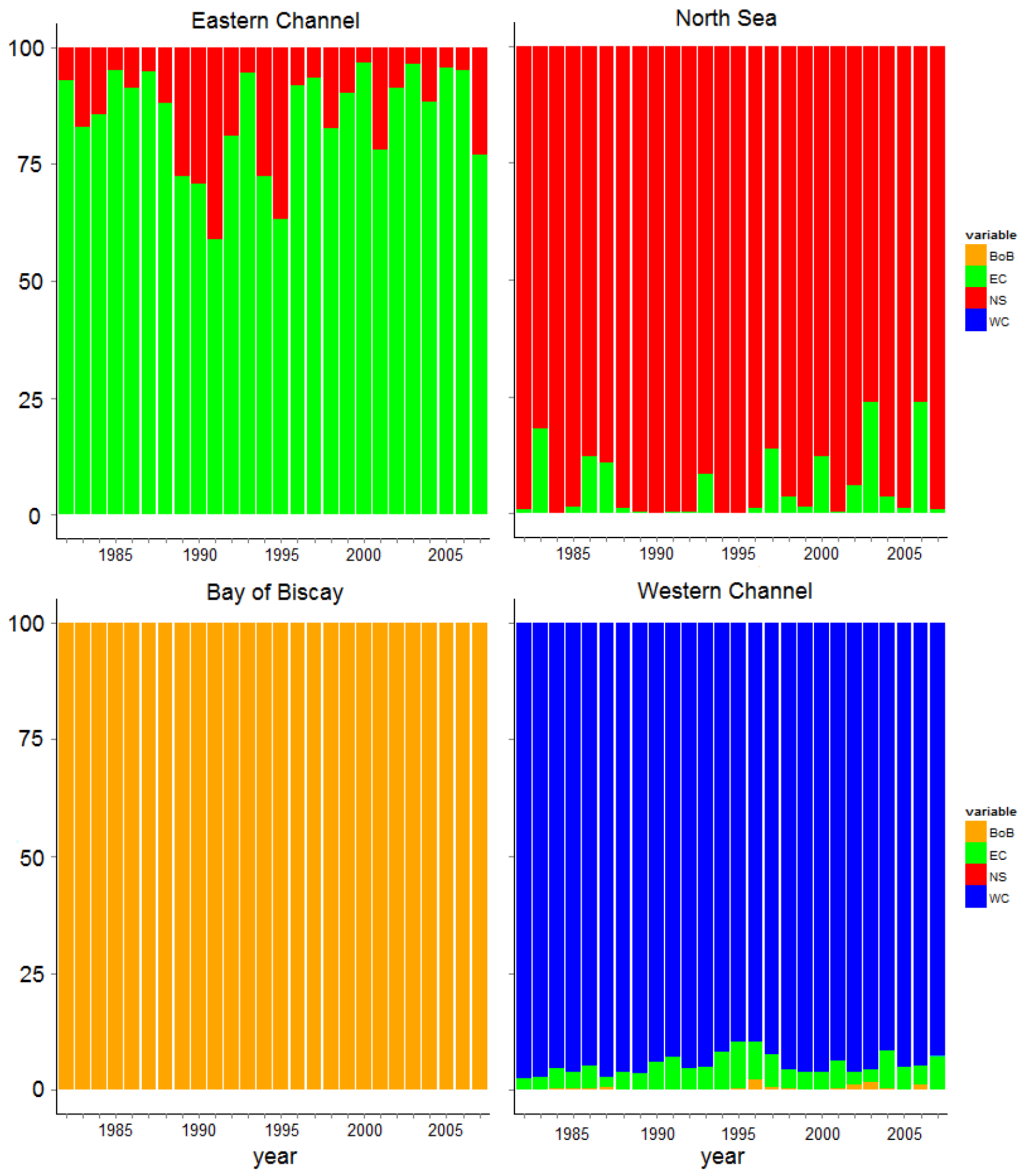

Figure 5 


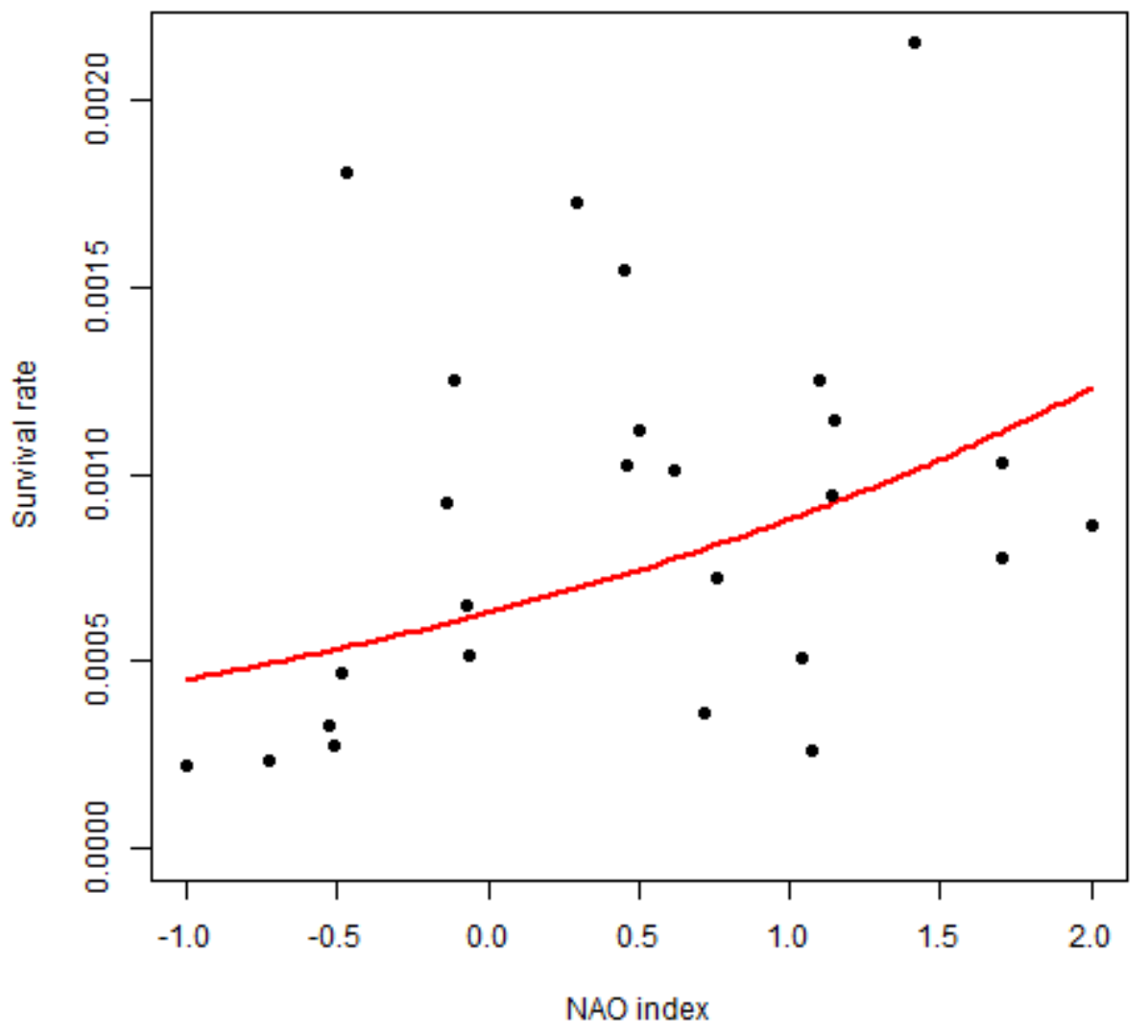

Figure 6 
Figures legends

Figure 1: Locations of the spawning sectors (streaked areas) and nursery sectors (grey polygons) within the area covered by the hydrodynamic model. The populations of interest are: the southern North Sea (NS), the Eastern English Channel (EC), the Western English Channel (WC), the Bay of Biscay (BoB).

Figure 2: Average proportion (1982-2007) of eggs turning into larvae and reaching metamorphosis, settling in the same region as the population from which they were spawned, and settling in nurseries from other regions. BoB: Bay of Biscay, WC: Western Channel, NS: North Sea, and EC: Eastern Channel.

Figure 3: Survival rates in the four populations: time series (solid lines) and averages (1982-2007, dotted lines). WC: Western Channel, NS: North Sea, EC: Eastern Channel, BoB: Bay of Biscay.

Figure 4: Number of settled larvae per number of eggs spawned for each region. Variance explained ( $\mathrm{r}^{2}$ of linear models): Eastern Channel $29 \%$, Western Channel : 63\%, North Sea : 50\%, $\mathrm{p}<0.01$ for all 3. Not significant for Bay of Biscay.

Figure 5: Proportion of the larvae settled in a given region (WC : Western Channel, NS : North Sea, BoB : Bay of Biscay, EC : Eastern Channel) coming from the four spawning regions (WC, NS, BoB, EC).

Figure 6: Survival rate in the Bay of Biscay vs NAO index. Black dots: survival rate (i.e., settled larvae vs eggs spawned) plotted as a function of the NAO index values for the spawning peak month of the corresponding years. Red line: Linear model using the logit-transformed survival rates as response variable $\left(\mathrm{p}<0.05, \mathrm{r}^{2}=17 \%\right)$. 
Table 1: Eggs and larvae development stages in the model and their characteristics.

\begin{tabular}{ccccc}
\hline Stages & Duration & Vertical movements & Mortality & $\begin{array}{c}\text { Ability to remain in } \\
\text { nurseries }\end{array}$ \\
\hline Eggs 1 & $\mathrm{T}^{\circ}$ dependent & Buoyancy & Size and $\mathrm{T}^{\circ}$ based & \\
Eggs 2 & $\mathrm{T}^{\circ}$ dependent & Buoyancy & Size and $\mathrm{T}^{\circ}$ based & \\
Eggs 3 & $\mathrm{T}^{\circ}$ dependent & Buoyancy & Size and $\mathrm{T}^{\circ}$ based & \\
Eggs 4 & $\mathrm{T}^{\circ}$ dependent & Passive & Size and $\mathrm{T}^{\circ}$ based & \\
Larvae 1 & $\mathrm{T}^{\circ}$ dependent & Passive & Fixed & Yes \\
Larvae 2 & $\mathrm{T}^{\circ}$ dependent & Vertical diel migration & Fixed & Yes \\
Larvae 3 & $\mathrm{T}^{\circ}$ dependent & Vertical diel migration & Fixed & Yes \\
Larvae 4 & Size dependent & Vertical diel migration & Fixed & \\
\hline
\end{tabular}


Table 2: Mean and variation coefficient (CV: Standard deviation/Mean) of annual larval survival rate (settling larvae per egg spawned) for each region.

\begin{tabular}{llllcc}
\hline Populations & All & Bay of Biscay & Western Channel & Eastern Channel & North Sea \\
\hline Mean & $7.1 \mathrm{E}-3$ & $9 \mathrm{E}-4$ & $2.55 \mathrm{E}-3$ & $2.58 \mathrm{E}-3$ & $3.9 \mathrm{E}-3$ \\
\hline $\mathrm{CV}$ & 0.20 & 59 & 0.25 & 0.34 & 0.30 \\
\hline
\end{tabular}


Table 3: Pearson coefficients calculated on annual larval survival rate time series by pairs (ns: non significant)

\begin{tabular}{lllll} 
& Bay of Biscay & Western Channel & Eastern Channel & North Sea \\
\hline Bay of Biscay & 1 & & & \\
Western Channel & ns & 1 & 1 \\
Eastern Channel & ns & 0.83 & 0.72 & 1 \\
North Sea & ns & 0.73 &
\end{tabular}


The following are the supplementary data related to this article.

Fig. S1. Number of eggs spawned each year for the four regions (NS: southern North Sea, EC: Eastern English Channel, WC: Western English Channel, BoB: Bay of Biscay).

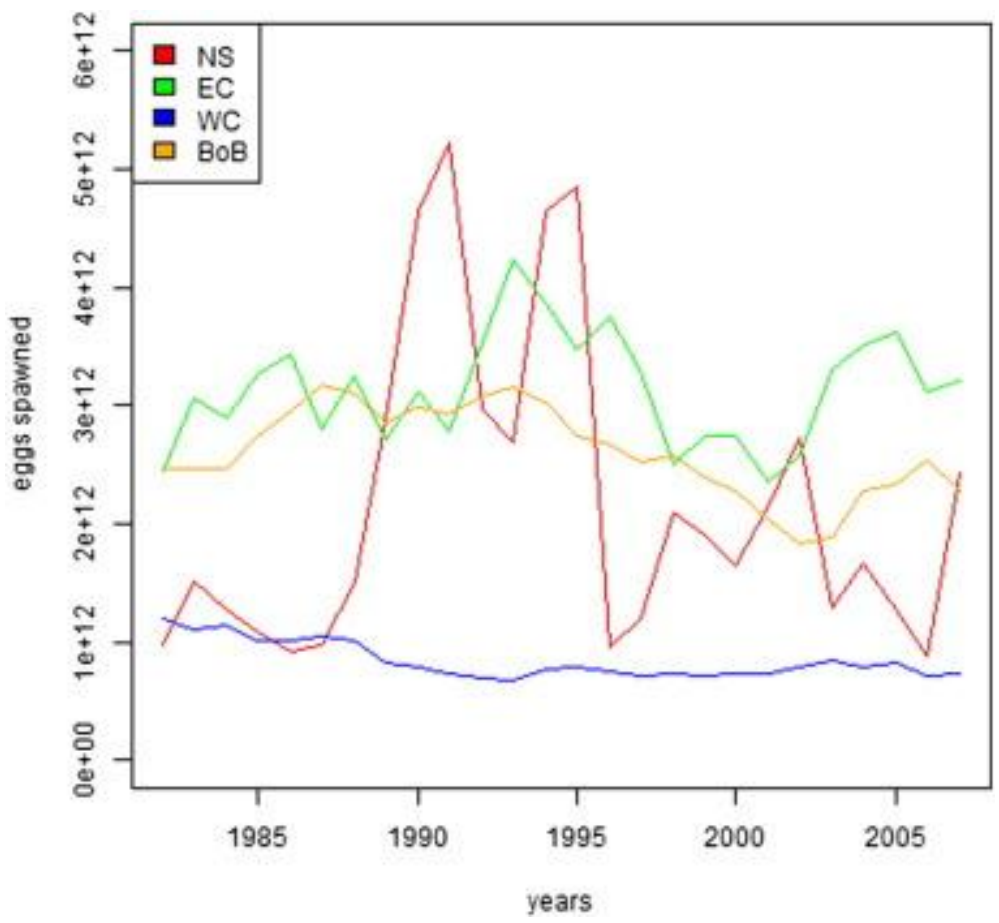

Fig. S2. Dates of the spawning peak in the four regions (NS: southern North Sea, EC: Eastern English Channel, WC: Western English Channel, BoB: Bay of Biscay).

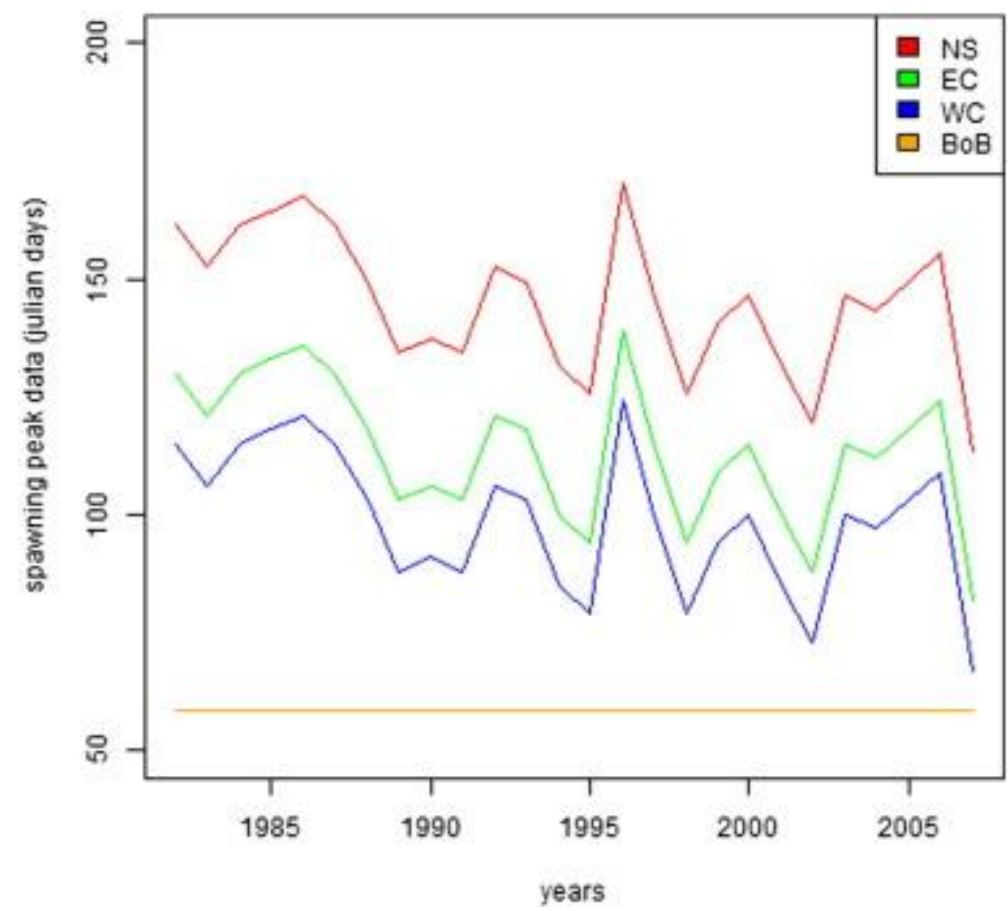


Fig. S3. Distribution of the super particles released in the southern North Sea, at the end of each run, for 5 starting dates (out of 10) and 3 years of interest. The colour corresponds to the proportion of larvae represented by each super particle still alive at the end of the run. The nurseries are highlighted in light pink.
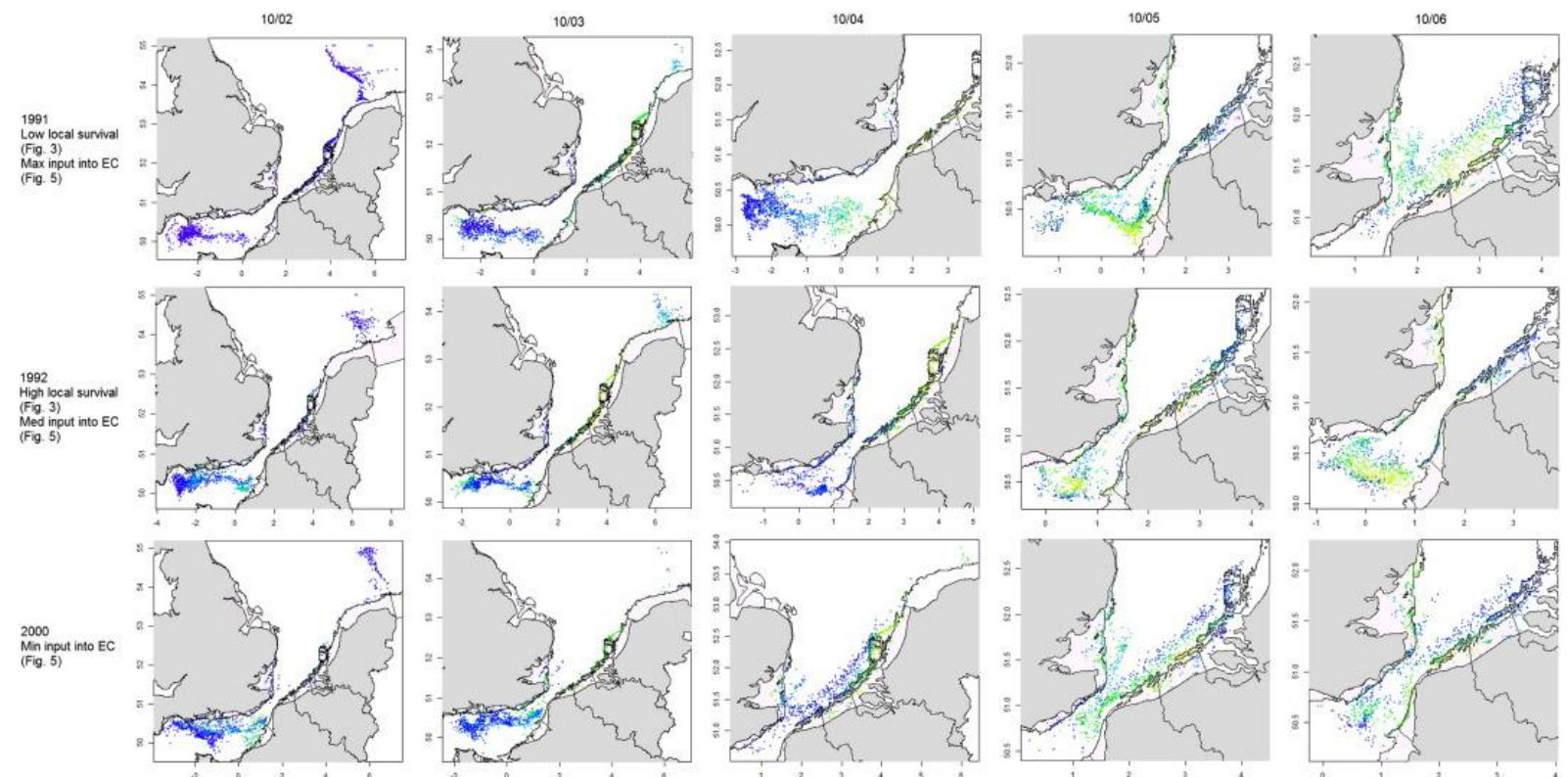

Fig. S4. Distribution of the super particles released in the Eastern English Channel, at the end of each run, for 5 starting dates (out of 10) and 3 years of interest. The colour corresponds to the proportion of larvae represented by each super particle still alive at the end of the run. The nurseries are highlighted in light pink.
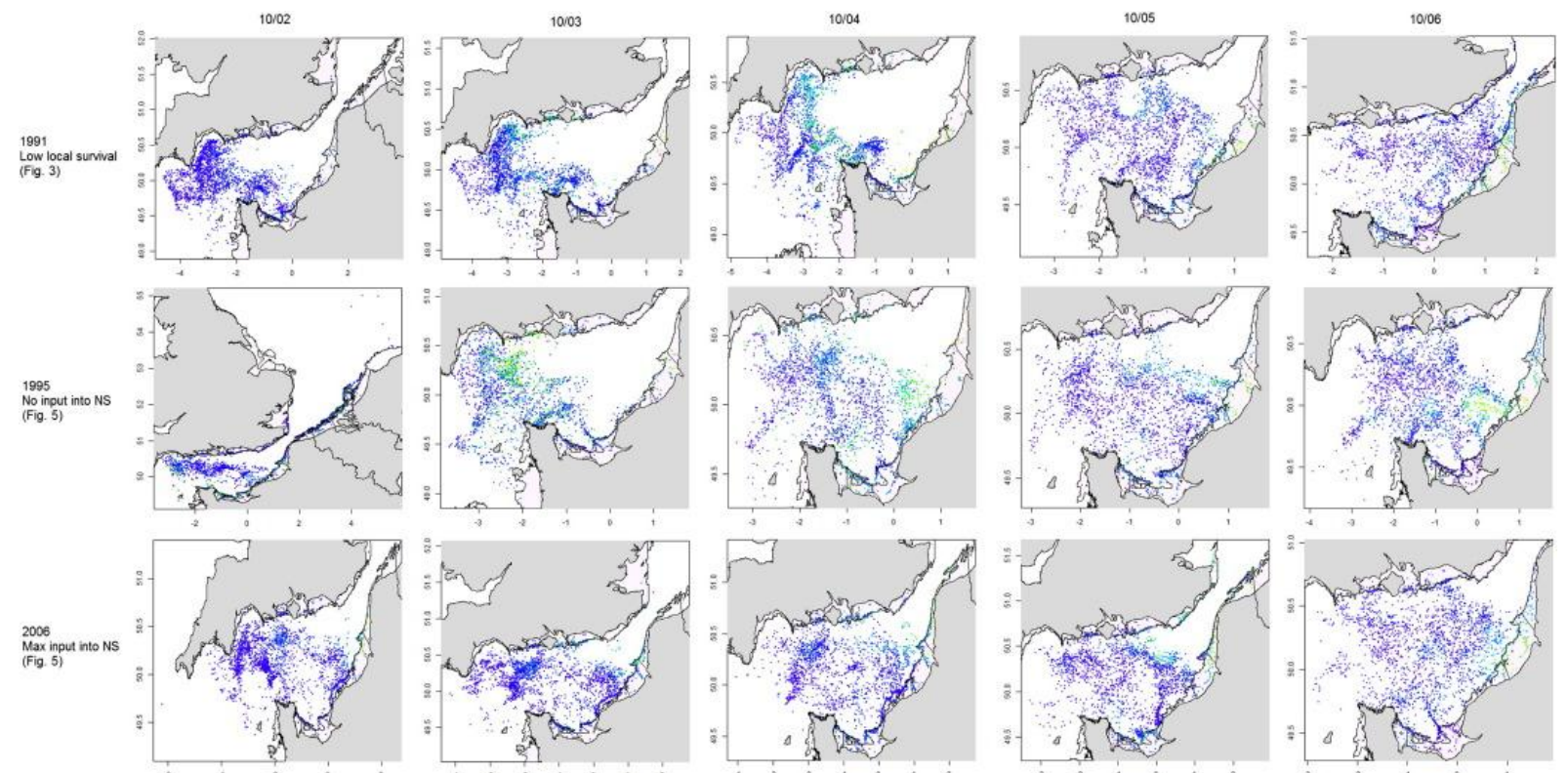